Proceedings of the 11th Polish-Japanese Joint Seminar on Micro and Nano Analysis, Gniew, September 11-14, 2016

\title{
Material Recovery of OFHC Cu and FeSi Steel after Processing by Plastic Deformations
}

\author{
T. Kvackaj*, R. Kocisko, J. Bidulska, M. Luptak and A. Kovacova \\ Technical University of Košice, Vysokoškolská 4, 04200 Košice, Slovakia
}

\begin{abstract}
The influence of thermoplastic processes through severe plastic deformations carried out at ambient temperature and through rolling carried out at cryogenic temperature on the recovery for two types of materials was investigated. As experimental materials, there were used oxygen free high conductivity copper and FeSi steel presenting materials with middle and high stacking fault energy, respectively. Both materials have been previously investigated, however mainly considering their material properties. In this study, oxygen free high conductivity $\mathrm{Cu}$ was processed by 13 passes through equal channel angular rolling which belongs to the severe plastic deformations group of methods. The rolling of FeSi steel at ambient and cryogenic temperatures was performed using a laboratory duo rolling mill, samples were rolled only by one pass. The aim of this study was to insert the strain to the materials with different stacking fault energy (middle and high) under ambient and cryogenic thermal conditions, respectively, and subsequently to observe the influence of stored energy on structural recovery of materials through differential scanning calorimetry method. This study implies that the recovery process characterized by the mobility of structural defects begins earlier for FeSi steel compared to oxygen free high conductivity $\mathrm{Cu}$.
\end{abstract}

DOI: 10.12693/APhysPolA.131.1315

PACS/topics: 61.82.Bg, 07.20.Mc, 81.20.Wk, 62.20.F-, 81.40.Ef

\section{Introduction}

The differential scanning calorimetry (DSC) is a thermo-analytical method used for measuring the difference in the amount of heat required for increase of the sample temperature and reference as a function of temperature. DSC analysis depends on a linear function of the sample holder temperature and time [1]. The three basic types of DSC can be recognized: heat flux DSC, power compensation DSC and hyper DSC. The most widely used is heat flux type of DSC (HF-DSC) with constant heating and cooling rates which have been applied extensively to the analysis of metals and alloys materials since 90th years of the last century $[2,3]$. The result from a DSC measurement is a curve of heat flux versus temperature or time. A DSC method is successfully used for the investigation of solid state reactions, such as precipitation, recovery, recrystallization, phase transformation and solid-liquid reactions in bulk and powder metallurgy (PM) metals [4].

In 90th years of the last century, research studies on DSC methods were focused on non-ferrous metals and their alloys with ultra fine grain (UFG) structure prepared by PM techniques [2-6]. In the early 21 st century, research observations were focused on bulk non-ferrous metals and their alloys with UFG structure [7-13]. The review paper [14] is mostly aimed at the analyze of UFG metals and alloys through the DSC method. Only few research works deal with a study of steels by DSC techniques $[15,16]$.

*corresponding author; e-mail: tibor.kvackaj@tuke.sk
The first information about the influence of plastic deformations at cryogenic temperature followed by heat treatment on UFG structure formation and mechanical properties in bulk pure $\mathrm{Cu}$ was published by Wang et al. [17]. The plastic deformations of steel at cryogenic temperatures are discussed by authors [14-16].

The DSC is an interesting method due to the opportunity for the calculation of processes activation energy (nucleation and grain growth) through the dependence of the peak temperature as it was described in $[18,19]$ and later in $[20]$ as follows:

$$
\ln \left(\frac{\beta}{T_{p}^{2}}\right)=-\frac{Q}{K_{b}} \frac{1}{T_{p}}+k_{0} .
$$

Editing Eq. (1), the following formula for activation energy of nucleation and grain growth can be obtained:

$$
Q=\left[k_{0}-\ln \left(\frac{\beta}{T_{p}^{2}}\right)\right] k_{\mathrm{B}} T_{p} \approx k_{0} k_{\mathrm{B}} T_{p} / 1000,
$$

where $k_{0}=1.63989572 \times 10^{25}$ - constant, $k_{\mathrm{B}}=1.38 \times$ $10^{-23}[\mathrm{~K}]$ - the Boltzmann constant, $\beta[\mathrm{K} / \mathrm{s}]$ - heating rate, $T_{p}[\mathrm{~K}]$ - peak temperature, $Q[\mathrm{~kJ} / \mathrm{mol}]$ - activation energy of nucleation and growth.

The aim of the present paper is to analyse two metallic materials base: oxygen free high conductivity (OFHC) $\mathrm{Cu}$ with UFG structure and $\mathrm{FeSi}$ steel processed by rolling at ambient and cryogenic temperature.

\section{Materials and experimental methods}

The experimental works were carried out on the oxygen free high purity copper (OFHC - 99.99\%) and steel based on FeSi with the chemical composition given in Table I.

A specimen $\left(7 \times 6 \mathrm{~mm}^{2}\right)$ from the OFHC Cu was processed by equal channel angular rolling (ECAR) having 
TABLE I

Local chemical analysis of C-Si steel (wt\%).

\begin{tabular}{c|c|c|c|c|c|c|c}
\hline \hline $\mathrm{C}$ & $\mathrm{Mn}$ & $\mathrm{Al}$ & $\mathrm{Si}$ & $\mathrm{P}$ & $\mathrm{S}$ & $\mathrm{Cu}$ & $\mathrm{Fe}$ \\
\hline 0.003 & 0.234 & 0.41 & 3.46 & 0.009 & 0.001 & 0.018 & 95.8
\end{tabular}

a matrix channel angle $\Phi=90^{\circ}$, rotated by route A (the billet is not rotated around vertical axis from pass to pass of ECAP). Details about experimental conditions are described in [21,22]. Subsequently, samples were subjected to uni-axial static tensile tests and DSC measurements. Samples from FeSi steel were rolled using a DUO 210 rolling mill in laboratory. Cryogenic conditions were achieved by cooling of samples in liquid nitrogen followed by rolling at temperature of $T_{\text {def }} \in\langle-120 ;-40\rangle\left[{ }^{\circ} \mathrm{C}\right]$. Thickness reductions of samples through cold rolling were in an interval $\varepsilon_{\text {cold }} \in\langle 2 ; 20\rangle[\%]$ vs. one pass.

\section{Results and discussion}

\subsection{OFHC Cu processed by ECAR}

The mechanical properties resulting from static tensile tests after ECAR passes are shown in Fig. 1.

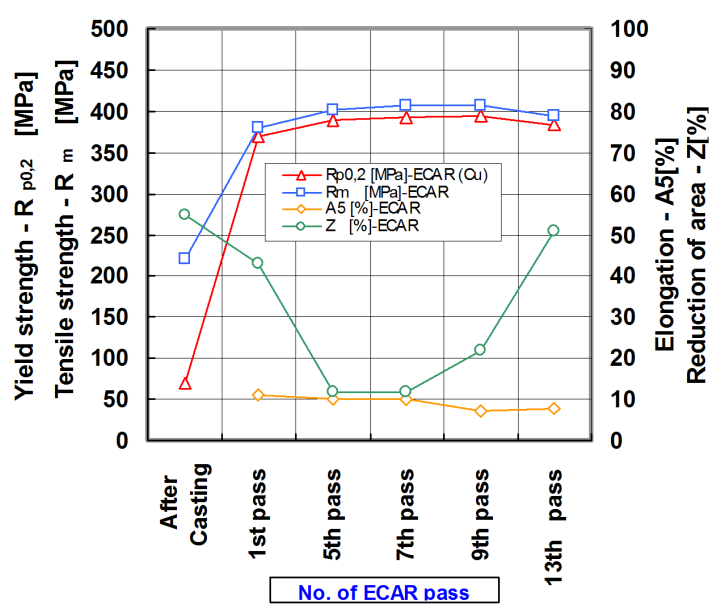

Fig. 1. Dependence of mechanical properties on the number of ECAR passes.

The maximal effect of deformation strengthening in a sample was registered already after the 1st ECAR pass. The following ECAR passes (2nd up to 9th) increased yield strength and tensile strength $\left(R_{P 0,2}, R_{m}\right)$ by the increment $\Delta R \approx 50 \mathrm{MPa}$. From the 9 th up to 13 th pass, there was observed a weak decrease of strength properties. Reduction of area as a significant parameter of plasticity was reduced with the strength increase and was stabilized at a minimal value between the 5th and 7 th pass. Reduction of area was $51 \%$ after 7 ECAR passes. The elongation was about the value of $10 \%$ and cannot be considered as a reliable parameter as gauge length of samples was short. The UFG elongated structure with an average subgrain diameter of $d_{s g, a v e}=735 \mathrm{~nm}$ and effective strain of $\varphi=8.0$ after 5 ECAR passes led to the rising of strength properties and changes in the reduction of area [22]. The analysis of the strengthening contributions revealed that the increase in strength properties up to the 5th pass is caused by a strong interactive effect resulting from the grain size refinement and increase of the dislocation density. In this stage, dislocation density is mainly generated from the Frank-Read sources. Increase of the dislocation density caused by the formation of low angle grain boundaries (LAGBs) from high angle grain boundaries (HAGBs) began after the 5 th pass. The dependence of activation energy on nucleation and grain growth calculated according to Eq. (2) is given in Fig. 2.

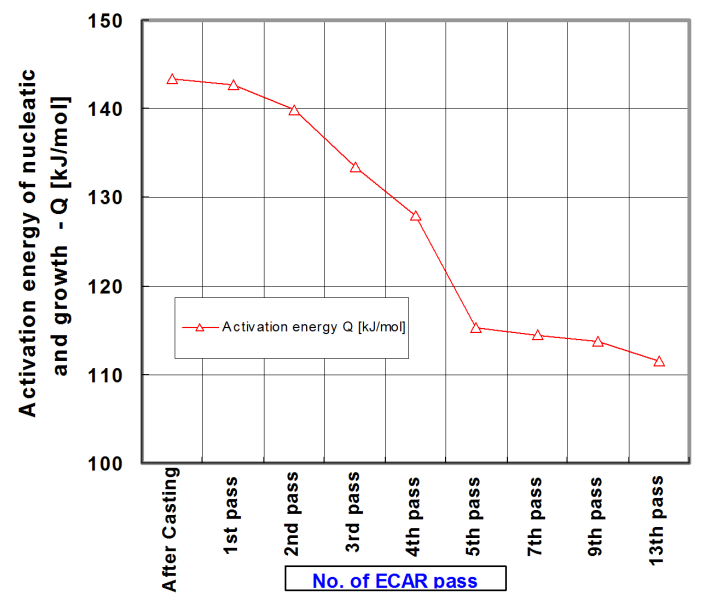

Fig. 2. Dependence of activation energy on the number of ECAR passes.

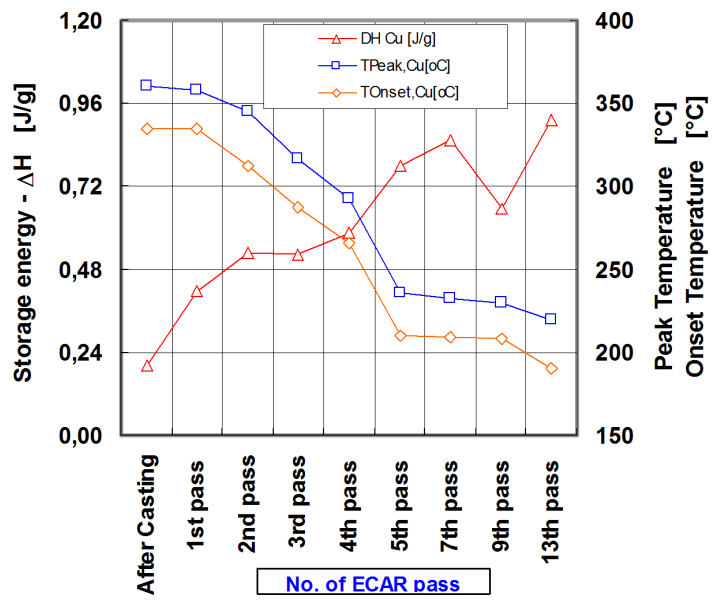

Fig. 3. DSC analysis of $\mathrm{OFHC} \mathrm{Cu}$ on the number of ECAR passes.

This graphical dependence confirms that after 5th pass, there are created favorable energetic conditions for the transformation of the LAGBs to the HAGBs. Therefore, the changes leading to the re-growth in reduction of area can be observed.

The differential scanning calorimetry (DSC) analysis given in Fig. 3 confirmed the previous implication that 
after the 5th ECAR pass, mechanical properties become stable.

According to the DSC analysis, stored energy expressed through the enthalpy is continuously increasing with the number of passes, peak and onset temperatures as well as homological temperature $\left(T_{\text {onset }} / T_{\text {melt }}\right)$ are stabilized after the 5 th pass. The graphical dependence shows that the static recovery obtained by the mobility of structural defects in the sample after casting started at $0.31 T_{\text {melt }}$ and after processing by 5 th ECAR passes started at $0.19 T_{\text {melt }}$.

\subsection{FeSi steel processed by cryorolling}

The DSC curves of FeSi steel are shown in Fig. 4.

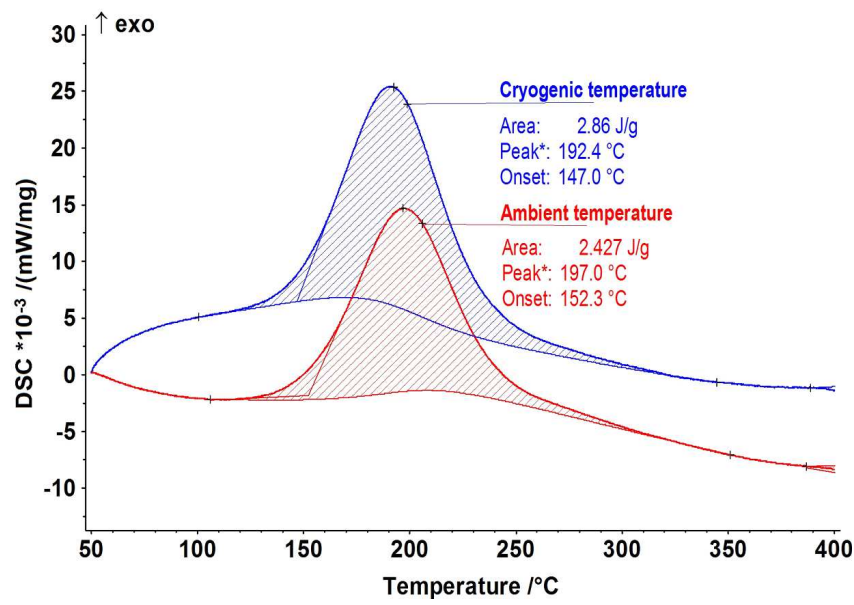

Fig. 4. DSC analysis of $\mathrm{FeSi}\left(\varepsilon_{a m b}=17 \%\right.$, $\left.\varepsilon_{\text {cryo }}=19 \%\right)$.

For each sample which were deformed approximately with the equal thickness deformation, a broad exothermic peak was observed from DSC analysis that implies a recovery process in the microstructure. Stored energy in both cases (cryogenic and ambient temperatures) was measured out as follows: $2.86 \mathrm{~J} / \mathrm{g}$ and $2.427 \mathrm{~J} / \mathrm{g}$, respectively. Even, it was found that the onset and peak temperatures for cryogenic and ambient conditions were shifted from the $147.0^{\circ} \mathrm{C}$ at $152.3^{\circ} \mathrm{C}$ and from the $192.4^{\circ} \mathrm{C}$ at $197.0^{\circ} \mathrm{C}$, respectively. Besides, released onset points (DSC analysis) implies that static recovery through the structural defects mobility starts at $0.1 T_{\text {melt }}$ for ambient conditions and at $0.0956 T_{\text {melt }}$ for cryogenic conditions, respectively. Considering cryogenic conditions, observed shifts are explained through the outcome of the stored energy increase which is introduced to the material during plastic deformation under cryogenic conditions that consequently results in the rising of driving force for the static recovery process. It is well-known that OFHC $\mathrm{Cu}$ is a material with fcc crystal structure and middle stacking fault energy (SFE) $\gamma_{s f e}=78 \mathrm{~mJ} / \mathrm{m}^{2}$ and ferrite of $\mathrm{FeSi}$ steel is a material with bcc crystal structure and high SFE $\gamma_{s f e}=180 \mathrm{~mJ} / \mathrm{m}^{2}$. For materials with bcc crystal structure, slip is a main plastic deformation mechanism, dynamic recovery, static recov- ery and static recrystallization are main active softening mechanisms of deformed structures.

On the other hand, ferrite is a material with high SFE, formation of the twins and deformation bands cannot be expected as a main deformation mechanism under normal plastic deformation conditions [23]. However, when the deformation is carried out at the cryogenic temperature, deformation slip and dynamic recovery are broken and the formation of twins and deformation bands was observed. The DSC measurement confirmed that during deformation processes, the stored energy was implemented into the structure, however without any possibility of relaxation by dynamic recovery. Stored energy is released in the next thermal cycle as static recovery through the structural defects mobility. In a material with fcc crystal structure and middle SFE (OFHC $\mathrm{Cu}$ ), slip is simple and a main active softening mechanism of deformed structures is static and dynamic recrystallization. Also, additional deformation mechanisms are twining and shear bands. The authors [24] described that the twinning is a major deformation mode in fcc metals with $\gamma_{s f e}<25 \mathrm{~mJ} / \mathrm{m}^{2}$ and those materials tend to deform by twinning if deformation temperature is decreasing or strain rate is increasing. The formation of shear bands depends on the magnitude of the shear strain. According to Ref. [24], the number of shear bands rapidly increases if the strain is in the range of $0.8<\varphi<2.6$ and formation of shear bands seems to be a major deformation mode which was also experimentally confirmed.

The calorimetric measurements on two material grades with bcc and fcc crystal structure show that stored energy was approximately 3 times higher in bcc than in fcc material. Moreover, homological temperature that represents the start of static recovery/static recrystallization was approximately 2.5 times higher in fcc material than in bcc material. For both material grades, deformation slip is a fundamental deformation mechanism. When deformations are very strong then additional deformation mechanisms are coming into the account: for bcc material, there are twinning and deformation bands and for fcc material, there are twining and shear bands. Stored energy measured in bcc material after processing at cryogenic temperature (cryorolling) was higher than in fcc material processing at $100^{\circ} \mathrm{C}$ (ECAR) that means additional deformation mechanism is activated more simply in fcc material. If stored energy is higher in bcc metal that means static recovery/static recrystallization starts easily in bcc material than in fcc material.

A comparison for two types of testing materials based on DSC analysis is shown in Table II.

\section{Conclusions}

The present paper provides a literary overview of the differential scanning calorimetry application in the materials identification. According to this experimental study, following important findings can be summarized:

- five ECAR passes have a strong effect on improving the $\mathrm{OFHC} \mathrm{Cu}$ properties, 
TABLE II

Comparison of data for two type of materials based on DSC analysis.

\begin{tabular}{|c|c|c|c|}
\hline \multirow{2}{*}{ material } & \multirow{2}{*}{$\mathrm{OFHC}-\mathrm{Cu}$} & \multicolumn{2}{|c|}{ steel: C-Si } \\
\hline & & ambient & cryogenic \\
\hline SFE: $\gamma_{s f e}\left[\mathrm{~mJ} / \mathrm{m}^{2}\right]$ & 78 & \multicolumn{2}{|c|}{180} \\
\hline crystallography net & fcc & \multicolumn{2}{|c|}{ bcc } \\
\hline main plastic & \multicolumn{3}{|c|}{ slip } \\
\hline additional plastic & \multicolumn{3}{|c|}{ twining + shear bands } \\
\hline softening mechanisms & \multicolumn{3}{|c|}{$\begin{array}{c}\text { dynamic recovery }+ \\
\text { dynamic recrystallization }+ \\
\text { static recrystallization }\end{array}$} \\
\hline \multirow{2}{*}{$\begin{array}{c}\text { stored energy: } \Delta H[\mathrm{~J} / \mathrm{g}] \\
\text { peak temperature: } \\
T_{\text {peak }}\left[{ }^{\circ} \mathrm{C}\right]\end{array}$} & $0.2-0.96$ & 2.427 & 2.86 \\
\hline & $220-360$ & 197.0 & 192.4 \\
\hline $\begin{array}{c}\text { onset temperature: } \\
T_{\text {onset }}\left[{ }^{\circ} \mathrm{C}\right]\end{array}$ & $190-335$ & 152.3 & 147.0 \\
\hline $\begin{array}{l}\text { homological temperature: } \\
\qquad\left(\frac{T_{\text {onset }}}{T_{\text {melt }}}\right)=K_{x}\end{array}$ & $0.18-0.31$ & 0.1 & 0.096 \\
\hline$\frac{\Delta H_{\text {steel }, a v}}{\Delta H_{C u, a v}}$ & \multicolumn{3}{|c|}{4.5} \\
\hline$\frac{K_{C u, a v}}{K_{\text {steel }, a v}}$ & \multicolumn{3}{|c|}{2.5} \\
\hline
\end{tabular}

- a recovery process is developed by the start in mobility of structural defects as follows:

- OFHC $\mathrm{Cu}$ is a material with middle SFE and fcc crystal structure which shows the decrease in stored energy and the shift in the recovery processes starting from $0.31 T_{\text {melt }}$ (without ECAR) to $0.19 T_{\text {melt }}$ (after 5 th ECAR passes),

- ferrite structure of FeSi steel having high SFE and bcc crystal structure deformed at different temperatures provides the shifting of the recovery processes from $0.1 T_{\text {melt }}$ (ambient temperature) to $0.096 T_{\text {melt }}$ (cryogenic temperature) and also enhancing the stored energy,

- the average value of stored energy for FeSi steel is 4.5 more than for $\mathrm{OFHC} \mathrm{Cu}$.

\section{Acknowledgments}

Authors are grateful for the support of experimental works by project VEGA $1 / 0325 / 14$. This work was also realized within the frame of the project "Technological preparation of electrotechnical steels with high permeability for electrodrives with higher efficiency" which is supported by the Operational Program "Research and Development" ITMS 26220220037, financed through European Regional Development Fund.

\section{References}

[1] G. Höhne, W.F. Hemminger, H.-J. Flammersheim, Differential Scanning Calorimetry, Springer-Verlag, Berlin 2003.

[2] L.C. Chen, F. Spaepen, J. Appl. Phys. 69, 679 (1991).
[3] B. Gunther, A. Kumpmann, H.D. Kunze, Scr. Metall. Mater. 27, 833 (1992).

[4] R.L. Danly, Thermochim. Acta 395, 201 (2002).

[5] A. Kumpmann, B. Gunther, H.D. Kunze, Mater. Sci. Eng. A 168, 165 (1993).

[6] Y.K. Huang, A.A. Menovsky, F.R. Boer, Nanostr. Mater. 2, 587 (1993).

[7] H. Jiang, Y.T. Zhu, D.P. Butt, I.V. Alexandrov, T.C. Lowe, Mater. Sci. Eng. A 290, 128 (2000).

[8] A.P. Zhilyaev, G.V. Nurislamova, S. Surinach, M.D. Baró, T.G. Langdon, Mater. Phys. Mech. 5, 23 (2002).

[9] T. Kvačkaj, A. Kováčová, R. Kočiško, Acta Phys. Pol. A 128, 689 (2015).

[10] K. Wei, P. Liu, Z. Ma, W. Wei, I.V. Alexandrov, J. Hu, Acta Metall. Slov. 21, 4 (2015).

[11] T. Kvačkaj, R. Bidulský, A. Kováčová, J. Ileninová, J. Bidulská, Acta Metall. Slov. 20, 397 (2014).

[12] B. Mingler, O.B. Kulyasova, R.K. Islamgaliev, G. Korb, H.P. Karnthaler, M.J. Zehetbauer, J. Mater. Sci. 42, 1477 (2007).

[13] Z. Hegedus, J. Gubicza, M. Kawasaki, N.Q. Chinh, J.L. Labar, T.G. Langdon, Mater. Sci. Forum 729, $222(2013)$.

[14] N. Gao, Mater. Sci. Forum 584-586, 255 (2008).

[15] M. Gojic, M. Suceska, M. Rajic, J. Therm. Anal. Calorim. 75, 947 (2004).

[16] T. Kvačkaj, R. Kocisko, R. Bidulsky, J. Bidulská, P. Bella, M. Lupták, A. Kovacova, J. Bacsó, Mater. Sci. Forum 782, 379 (2014).

[17] Y. Wang, M. Chen, F. Zhou, E. Ma, Nature 419, 912 (2002).

[18] H.E. Kissinger, Anal. Chem. 29, 1702 (1957).

[19] L.C. Chen, F. Spaepen, J. Appl. Phys. 69, 679 (1991).

[20] J. Gubicza, S.V. Dobatkin, E. Khosravi, A.A. Kuznetsov, J.L. Lábár, Mater. Sci. Eng. A 528, 1828 (2011).

[21] M. Kvačkaj, T. Kvačkaj, A. Kováčová, R. Kočiško, J. Bacsó, Acta Metall. Slov. 16, 84 (2010).

[22] T. Kvačkaj, A. Kovačová, M. Kvačkaj, R. Kočiško, L. Litynska-Dobrzynska, V. Stoyka, M. Mihaliková, Micron 43, 720 (2012).

[23] S. Qu, X.H. An, H.J. Yang, C.X. Huang, G. Yang, Q.S. Zang, Z.G. Wang, S.D. Wu, Z.F. Zhang, Acta Mater. 57, 1586 (2009).

[24] F.J. Humphreys, M. Hatherly, Recrystallization and Related Annealing Phenomena, 2nd ed., Elsevier, Oxford 2004 . 